\title{
Determinação do ponto de colheita de diferentes cultivares de maracujá
}

\author{
Juliana L. V. dos Santos' ${ }^{1}$, Eder D. de Resende', Derliane R. Martins', \\ Geraldo de A. Gravina ${ }^{2}$, Sergio A. Cenci $^{3}$ \& José F. M. Maldonado ${ }^{4}$
}

\begin{abstract}
RESUMO
Neste trabalho caracterizou-se a qualidade dos frutos em diferentes pontos de colheita para armazenamento das cultivares de maracujá: BRS Gigante Amarelo, BRS Ouro Vermelho e BRS Sol do Cerrado. Foram avaliados as características físicas dos frutos (aparência, perda de massa, coloração da casca) e os parâmetros químicos do suco (conteúdo de acidez, pH, ácido ascórbico, sólidos solúveis totais, açúcares solúveis totais e açúcares redutores). Utilizou-se uma Amostragem Simples ao Acaso (ASA), com 0,05 de significância e as médias foram comparadas pelo Teste " $\mathrm{t}$ " por Intervalo de Confiança. Os frutos colhidos nos estádios iniciais de amadurecimento apresentaram maior perda de massa e alteração da qualidade do suco. Conclui-se que os frutos das diferentes cultivares colhidos na safra de verão (novembro/dezembro) devem ter pelo menos $55 \%$ de casca com coloração amarela para proporcionar menor perda de massa, manter a qualidade do suco e aumentar a sua vida útil.
\end{abstract}

Palavras-chave: Passiflora edulis, estádios de maturação, BRS Gigante Amarelo, BRS Ouro Vermelho, BRS Sol do Cerrado

\section{Determination of the harvest point of different passion fruit cultivars}

\begin{abstract}
In this study the fruit quality was characterized at different harvest points for storage of varieties of passion fruits: BRS Gigante Amarelo, BRS Ouro Vermelho and BRS Sol do Cerrado. The physical characteristics of fruits (appearance, mass loss and peel color) and chemical parameters of juice (content of acidity, $\mathrm{pH}$, ascorbic acid, total soluble solids, total soluble sugars and reducing sugars) were characterized. The method of Simple Random Sampling (SRS) was applied, with 0.05 level of significance, and means were compared using the " $\mathrm{t}$ " Test for Confidence Intervals. Fruits harvested in the early ripening stages showed a higher mass loss as well as the worst juice quality. It was concluded that fruits of different cultivars harvested in summer seasons must present at least $55 \%$ of yellow peel color to render the lower mass loss, the best quality of juice and to extend the storage time.
\end{abstract}

Key words: Passiflora edulis, maturation stages, BRS Gigante Amarelo, BRS Ouro Vermelho, BRS Sol do Cerrado

\footnotetext{
${ }^{1}$ Laboratório de Tecnologia de Alimentos/UENF, Av. Alberto Lamego, 2000, Bairro Parque Califórnia, CEP 28013-602, Campos dos Goytacazes, RJ. Fone: (22) 2739-7346, E-maill: julauredo@yahoo.com.br; eresende@uenf.br; derliane.martins@bol.com.br

${ }^{2}$ Laboratório de Engenharia Agrícola/UENF. Fone: (22) 2748-6468, E-maill: gravina@uenf.br

${ }^{3}$ Laboratório de Fisiologia Pós-colheita, Embrapa Agroindústria de Alimentos, Av. das Américas, 29501, CEP 23020-470, Guaratiba, RJ. Fone: (21) 3622-9641. E-mail: cenci@ctaa.embrapa.br

${ }^{4}$ PESAGRO-RIO - Estação Experimental de Macaé, Estrada Velha do Glicério, Km 3, CEP 27901-970, Macaé, RJ. Fone: (22) 2765-1935. E-mail: franciscopesagro@hotmail.com
} 


\section{INTRODUÇÃO}

O maracujazeiro é uma frutífera da família Passifloracea bastante cultivada e explorada de norte a sul do território brasileiro, com bom retorno econômico. O maracujá-amarelo ou maracujá-azedo (Passiflora edulis Sims) é nativo da América do Sul e amplamente cultivado em países tropicais e subtropicais (Lima, 2002).

Os maiores produtores mundiais de maracujá se localizam na América do Sul, sendo o Brasil, a Colômbia, o Peru e o Equador, os maiores exportadores. Segundo dados do Instituto Brasileiro de Geografia e Estatística - IBGE (2011) em 2010 a produção brasileira chegou a $920.158 \mathrm{t}$ de frutos em uma área plantada de 62.019 ha, com rendimento médio de $14.836 \mathrm{~kg}$ $\mathrm{ha}^{-1}$. Os estados com maiores produções são: Bahia (461.105 t), Ceará (159.886 t), Espírito Santo (46.506 t), Sergipe (45.956 t), Minas Gerais (37.001 t) e São Paulo (30.743 t).

O maracujá-azedo é atacado por várias doenças que depreciam a qualidade do fruto, reduzem a produtividade e a longevidade da cultura. As doenças mais prejudiciais são causadas por vírus (virose do endurecimento do fruto - PWV), por fungos, como a antracnose (Colletotrichum gloeosporioides), verrugose (Cladosporium spp.) e septoriose (Septoria passiflorae) e pela bactéria Xanthomonas axonopodis pv. passiflorae (Junqueira et al., 2003).

Com a finalidade de controlar essas doenças, exceto a virose, os produtores vêm aplicando fungicidas e antibióticos cujos custos vêm aumentando a cada ano podendo inviabilizar, em breve, essa atividade econômica. Além disto, é cada vez maior o número de consumidores preocupados com o conceito de qualidade mercadológica e com a preservação do ambiente. Por esta razão, procuram frutas saudáveis e sem resíduos de agrotóxicos. Esta é, sem dúvida, uma tendência mundial irreversível e, neste contexto, o uso de cultivares resistentes associado a outras técnicas de manejo integrado é a medida mais eficaz, econômica e ecológica de controle de doenças e pragas (Junqueira et al., 2003).

No período de 2005 a 2008 a Embrapa Cerrados desenvolveu as cultivares de maracujá BRS Gigante Amarelo, BRS Ouro Vermelho e BRS Sol do Cerrado, em que o objetivo principal foi obter cultivares produtivas e resistentes a múltiplas doenças (Faleiro et al., 2008). Referidos materiais estão sendo cultivados em diversas regiões do Brasil mas carecem de informações importantes acerca do comportamento no ambiente de produção. Os produtores e os técnicos necessitam de informações sobre o ponto de colheita e a qualidade desses materiais.

Em geral, a colheita do maracujá é efetuada quando os frutos caem no chão. Este procedimento pode levar à desidratação do fruto e à contaminação por micro-organismos reduzindo o período de conservação e de comercialização, acarretando perdas significativas. A determinação correta do estádio de maturação do fruto é essencial para que a colheita seja efetuada no momento adequado. Para isto, são utilizados os índices de maturação que compreendem características de coloração da casca ou alterações químicas que ocorrem ao longo do processo de maturação dos frutos, tais como acidez titulável (AT), sólidos solúveis (SS), conteúdo de açúcares, relação SS/AT, rendimento em suco, vitamina $\mathrm{C}$, clorofila e carotenoides totais do suco (Coelho et al., 2010).
Estudos para o maracujá-amarelo comum identificaram que os frutos da safra de inverno podem ser colhidos com pelo menos $30 \%$ de coloração amarela da casca, sem prejuízo de sua qualidade (Coelho et al., 2010). Contudo, essas informações não podem ser extrapoladas para as diferentes cultivares de maracujás que, normalmente, apresentam maior produção nas safras de verão.

Neste trabalho determinou-se o ponto adequado de colheita dos frutos na safra de verão das cultivares de maracujá BRS Gigante Amarelo, BRS Ouro Vermelho e BRS Sol do Cerrado, com o objetivo de garantir a qualidade durante o armazenamento e aumentar a vida útil dos frutos.

\section{Material e Métodos}

Os frutos foram obtidos de uma lavoura experimental da Pesagro, RJ, implantada em Janeiro/Fevereiro de 2008 em parceria com produtor rural do Distrito de Areias (MiracemaRJ). As cultivares BRS Gigante Amarelo, BRS Ouro Vermelho e BRS Sol do Cerrado foram plantadas em blocos casualizados, com quatro parcelas de 14 plantas para cada cultivar, em espaçamento de $3 \times 3 \mathrm{~m}$.

$\mathrm{Na}$ safra de novembro/dezembro de 2009 os frutos foram colhidos em quatro estádios de maturação: estádio-1 (uma pinta amarela); estádio-2 (metade do fruto amarelado); estádio-3 (dois terços do fruto amarelado) e estádio-4 (totalmente amarelado). No laboratório os frutos foram lavados e sanitizados em solução de água clorada a $100 \mathrm{ppm}$ por $15 \mathrm{~min}$ e secados com papel toalha. Metade de um lote de quarenta frutos de cada cultivar foi analisada no momento da colheita enquanto a outra metade (20 frutos) foi mantida sobre estantes de plástico em câmara de armazenamento a $22{ }^{\circ} \mathrm{C}$ e $90 \%$ UR até o amarelecimento completo da casca. Os frutos de cada cultivar colhidos maduros serviram como parâmetro de referência para o controle de qualidade.

A perda de massa (\%) foi medida em balança semianalítica (GEHAKA, modelo BC 2000), com resultados padronizados para $100 \mathrm{~g}$. A aparência foi caracterizada por meio de fotografias, conforme Martins (2005). A coloração da casca foi medida pelo Colorímetro de Hunter (MiniScan XE Plus) sendo a escala de cor obtida conforme Silva et al. (2008).

Para avaliações químicas o suco foi filtrado em tecido de algodão e congelado a $-18^{\circ} \mathrm{C}$ até o momento das análises. $\mathrm{O}$ conteúdo de sólidos solúveis totais $\left({ }^{\circ}\right.$ Brix) foi medido com um refratômetro digital. $\mathrm{O} \mathrm{pH}$ foi medido diretamente no suco da fruta utilizando-se o medidor WTW (Model 330). A acidez titulável (AT) foi medida em $2 \mathrm{~mL}$ de suco diluída em $50 \mathrm{~mL}$ de água destilada utilizando-se $\mathrm{NaOH} 0,1 \mathrm{~N}$, expresso em $\mathrm{g}$ ácido cítrico $100 \mathrm{~mL}^{-1}$. O conteúdo de ácido ascórbico (AA) foi medido em $2 \mathrm{~mL}$ de suco com $5 \mathrm{~mL}$ de ácido oxálico, titulandose com 2,6 Dicloroindofenol (AOAC, 1994), com resultados em mg AA $100 \mathrm{~mL}^{-1}$. As medidas de açúcares redutores (AR) foram feitas com $5 \mathrm{~mL}$ de suco em $50 \mathrm{~mL}$ de água destilada e o licor de Soxhlet previamente padronizado com solução de glicose a $0,5 \%$ p/v (Lane \& Eynon, 1934). Os açúcares solúveis totais (AST) foram medidos após a hidrólise ácida a $70{ }^{\circ} \mathrm{C}$ de uma solução de $4 \mathrm{~mL}$ de suco e $2 \mathrm{~mL}$ de $\mathrm{HCl} 2 \mathrm{~N}$, neutralizada posteriormente com $3 \mathrm{~mL}$ de $\mathrm{NaOH} 1 \mathrm{~N}$ e diluída com $60 \mathrm{~mL}$ 
de água destilada. Os resultados de AR e AST foram expressos em g $100 \mathrm{~mL}^{-1}$.

Utilizou-se o método de amostragem simples ao acaso (ASA) considerando-se $5 \%$ de significância e o desvio de $10 \%$ em torno da média de uma população infinita de frutos. As médias de análises de 20 frutos foram comparadas pelo Teste ' $\mathrm{t}$ ' de Student através do Sistema de Análises Estatísticas e Genéticas (SAEG, 2007).

\section{Resultados e Discussão}

Amostragens de 20 frutos foram representativas de populações infinitas quando utilizadas para análises de cor, perda de massa e características químicas do suco. As medidas de açúcares redutores e de ácido ascórbico apresentaram maiores valores de coeficiente de variação, notadamente no estádio 1, conforme observado por Coelho et al. (2011b).

Os registros fotográficos dos maracujás das diferentes cultivares colhidos no estádio 1, caracterizaram manchas e enrugamento da casca ao final da estocagem, por 12 dias; no entanto, os frutos colhidos a partir do estádio 2 amadureceram normalmente, sem apresentar sintomas de enrugamento da casca ao final da estocagem, conforme Santos (2011).

O padrão de maturação dos frutos foi validado a partir das medidas do parâmetro de Hunter b indicando a proporção de coloração amarela da casca (Tabela 1) destacando-se entre os dados o estádio de maturação 2, que apresentou $56 \%$ de coloração amarela da casca. Segundo Silva et al. (2008) os maracujás-amarelos da safra de verão apresentam qualidade ótima para consumo quando são colhidos com $65 \%$ de coloração amarela da casca.

Tabela 1. Escala de cor da casca na ocasião da colheita em diferentes estádios de maturação dos frutos das cultivares de maracujá BRS Gigante Amarelo, BRS Ouro Vermelho e BRS Sol do Cerrado, no período de novembro e dezembro de $2009^{*}$

\begin{tabular}{cccc}
\hline \multirow{2}{*}{$\begin{array}{c}\text { Estádios de } \\
\text { maturação }\end{array}$} & $\begin{array}{c}\text { Gigante } \\
\text { Amarelo }\end{array}$ & $\begin{array}{c}\text { Ouro } \\
\text { Vermelho }\end{array}$ & $\begin{array}{c}\text { Sol do } \\
\text { Cerrado }\end{array}$ \\
\cline { 2 - 4 } & \multicolumn{2}{c}{ Coloração amarela da casca (\%) } \\
1 & $38,31( \pm 7,90)$ & $28,96( \pm 4,26)$ & $35,65( \pm 3,36)$ \\
2 & $55,52( \pm 6,70)$ & $54,12( \pm 6,75)$ & $58,39( \pm 3,43)$ \\
3 & $70,57( \pm 5,67)$ & $70,48( \pm 4,05)$ & $75,52( \pm 3,08)$ \\
4 & $87,67( \pm 2,95)$ & $81,99( \pm 2,72)$ & $83,43( \pm 3,66)$ \\
\hline
\end{tabular}

* As médias estão representadas com os intervalos de confiança a $p \leq 0,05$

Os frutos colhidos no estádio 1 alcançaram perda de massa de $8,88 \%( \pm 0,97)$ para BRS Gigante Amarelo; $8,52 \%( \pm 0,97)$ para BRS Ouro Vermelho e $8,89 \%( \pm 0,83)$ para BRS Sol do Cerrado (Figura 1) após 12 dias de estocagem. No estádio 2 a perda de massa média foi de $5,14 \%$ para as três cultivares, após 9 dias de estocagem. No estádio 3 a cultivar BRS Ouro Vermelho apresentou tendência de menor perda de massa alcançando média de $2,87 \%( \pm 0,28)$ durante 6 dias de estocagem ao passo que a BRS Gigante Amarelo alcançou 3,82\% $( \pm 0,55)$ e BRS Sol do Cerrado atingiu 3,72\% $( \pm 0,52)$.

De acordo com Coelho et al. (2011a) os maracujás colhidos com $30,7 \%$ de cor amarela amadurecem em 11 dias, a $22{ }^{\circ} \mathrm{C}$ e $90 \%$ UR, alcançando $4,6 \%$ de perda de massa. Os frutos

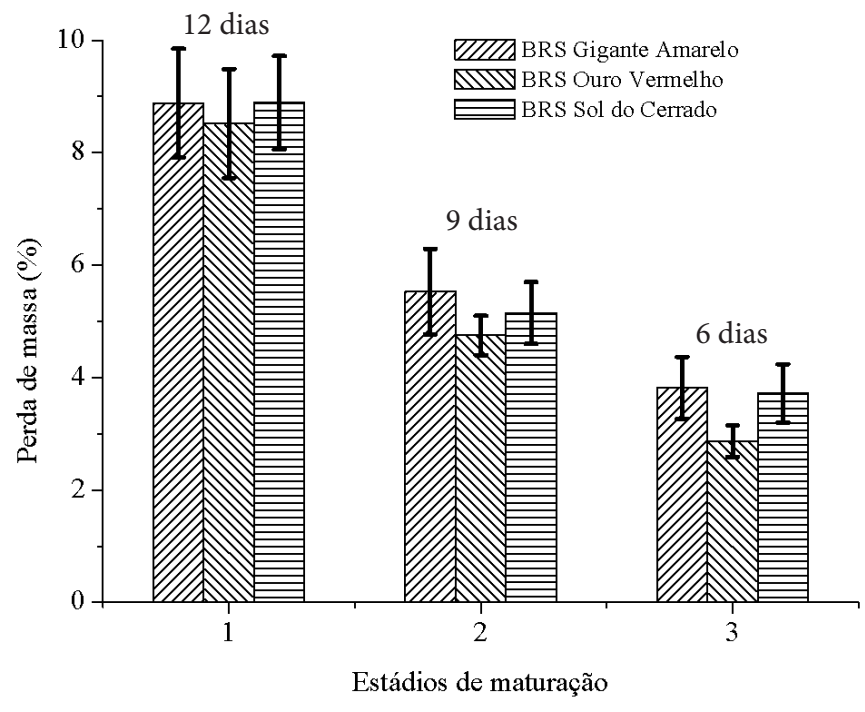

Obs.: Barras verticais estão representadas com os intervalos de confiança a $p \leq 0,05$

Figura 1. Perda de massa dos frutos das cultivares BRS Gigante Amarelo, BRS Ouro Vermelho e BRS Sol do Cerrado, colhidos em diferentes estádios de maturação e armazenados até o completo amadurecimento em câmara a $22{ }^{\circ} \mathrm{C}$ e $90 \%$ UR

colhidos com $66 \%$ de cor amarela amadurecem em 9 dias alcançando $3,14 \%$ e aqueles colhidos com $74,7 \%$ de cor amarela alcançam somente 2,1\% de perda de massa em 6 dias de estocagem. Em todos os casos não ocorre murchamento da casca, corroborando com os dados do presente experimento para as cultivares colhidas a partir do estádio 2 .

No estádio 1 as três cultivares apresentaram menores teores de SST quando comparados com os dos frutos maduros (estádio 4). A partir do estádio 2 não se observam diferenças de SST das cultivares BRS Ouro Vermelho e BRS Sol do Cerrado, com respeito aos frutos maduros (Figura 2). O BRS Gigante Amarelo (Figura 2A) apresentou tendência de aumento de SST durante o armazenamento quando colhido a partir de estádio 2 atingindo valores similares aos frutos maduros das duas outras cultivares.

O conteúdo de SST nos frutos maduros de BRS Gigante Amarelo (13,28 $\left.{ }^{\circ} \mathrm{Brix}\right)$ é similar àquele medido por Abreu et al. (2009) para a mesma cultivar (12,68 ${ }^{\circ}$ Brix). Pinheiro et al. (2006) avaliaram sucos integrais de maracujá de diferentes marcas encontrando teores de $12,5-13,3^{\circ}$ Brix. Coelho et al. (2010) constataram que os maracujás da safra de inverno colhidos com 30,7\% de coloração amarela, alcançaram teores ótimos de SST da ordem de $14,5^{\circ}$ Brix, valor este apreciado pelas indústrias.

Os açúcares redutores (AR) indicaram similaridade com SST (Figura 2). No estádio 1 os baixos teores de AR sinalizam que os frutos estavam imaturos com menor concentração de açúcares simples prontamente disponíveis para o metabolismo; mesmo assim, a partir do estádio 2 as cultivares BRS OV e BRS $\mathrm{SC}$ apresentaram teores ótimos de AR quando comparados com frutos maduros (estádio 4). No caso de BRS GA (Figura 2A) o conteúdo de AR foi mais elevado no estádio maduro $(8,93$

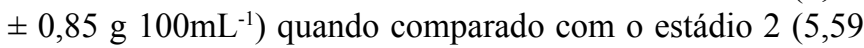

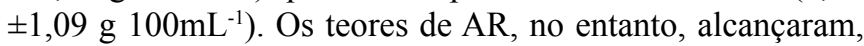
no estádio 2 , magnitudes similares às dos frutos de BRS OV e BRS SC colhidos maduros (Figuras 2B e 2C). 
A.

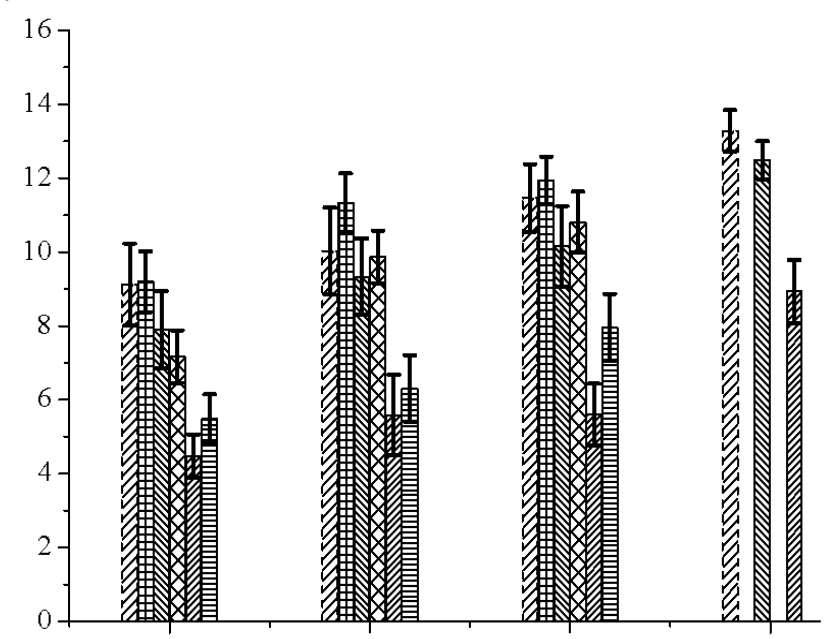

B.

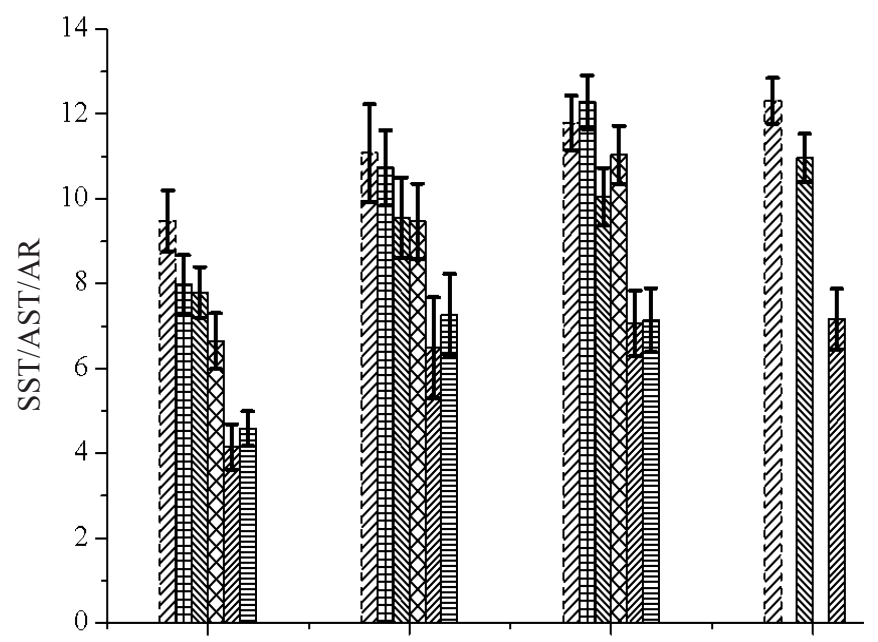

C.

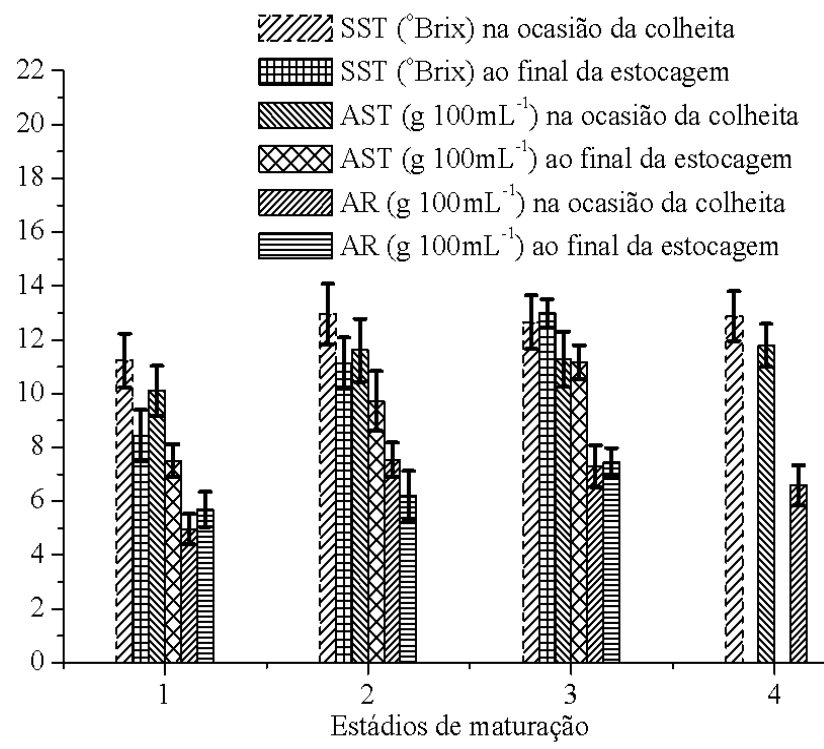

Obs.: Barras verticais estão representadas com os intervalos de confiança a $\mathrm{p} \leq 0,05$

Figura 2. Conteúdo de sólidos solúveis totais (SST), açúcares solúveis totais (AST) e açúcares redutores (AR) do suco das cultivares BRS Gigante Amarelo (A), BRS Ouro Vermelho (B) e BRS Sol do Cerrado (C) avaliados em diferentes estádios de maturação e após o amadurecimento em câmara a $22^{\circ} \mathrm{C}$ e $90 \%$ UR
Pinheiro et al. (2006) avaliaram marcas de sucos integrais apresentando valores de AR entre 6,8-13,3 g 100 g-1. Coelho et al. (2010) encontraram valores ótimos de AR de 5,11 g 100 $\mathrm{mL}^{-1}$ em maracujás-amarelos colhidos com $30,7 \%$ de coloração amarela da casca.

As medidas de açúcares solúveis totais (AST) também foram correlacionadas com medidas SST e AR, para as três cultivares de maracujá. No estádio 2 os frutos de BRS OV e BRS SC tiveram um conteúdo de $\mathrm{AST}$ similar àquele dos frutos colhidos maduros (Figuras 2B e 2C). A cultivar BRS GA apresentou tendência de aumentos progressivos de AST com os estádios de maturação mas os frutos colhidos no estádio 2 apresentaram médias de AST $\left(9,33 \pm 1,03 \mathrm{~g} 100 \mathrm{~mL}^{-1}\right)$ similares às dos frutos das cultivares BRS OV e BRS SC colhidos maduros.

A proporção entre AST e AR indica que o conteúdo de açúcares não-redutores permaneceu constante durante a maturação dos frutos na planta, nos frutos colhidos imaturos (estádio 1) tenha ocorrido um consumo efetivo de AST durante o armazenamento com destaque para a cultivar BRS SC que apresentou decréscimo expressivo, sinal de que mencionadas reservas de açúcares foram utilizadas durante a estocagem dos frutos porém, devido à sua condição imatura, eles não foram capazes de promover a síntese de novos açúcares. Segundo Chitarra \& Chitarra (2005) os frutos que não têm reserva de amido, como ocorre com o maracujá, utilizam a rota de síntese de açúcares a partir de ácidos orgânicos.

O consumo de ácidos orgânicos dos frutos no estádio 1 (Figura 3) é evidenciado pela redução da acidez durante o armazenamento sinalizando que os frutos das diferentes variedades não recompuseram ácidos após a colheita. A partir do estádio 2 os frutos estocados apresentaram a mesma acidez daqueles frutos colhidos maduros (estádio 4). Esses resultados corroboram com os observados por Coelho et al. (2010) nos quais o maracujá-amarelo comum colhido em estádio fisiológico

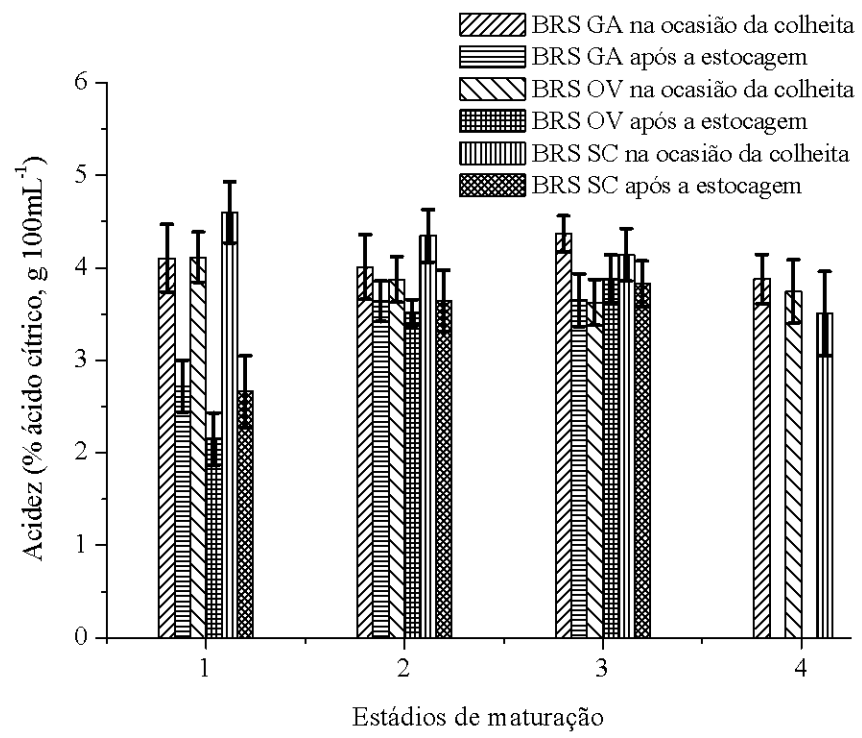

Obs.: Barras verticais estão representadas com intervalos de confiança a $p \leq 0,05$

Figura 3. Acidez do suco das cultivares BRS Gigante Amarelo (BRS GA), BRS Ouro Vermelho (BRS OV) e BRS Sol do Cerrado (BRS SC) avaliados em diferentes estádios de maturação e após o amadurecimento em câmara a $22{ }^{\circ} \mathrm{C}$ e $90 \%$ UR 
maturo apresenta índices de acidez de mesma magnitude daqueles frutos colhidos maduros quando avaliados após a estocagem.

Os frutos da cultivar BRS GA colhidos maduros apresentaram média de acidez total de $3,88 \%( \pm 0,27)$ inferior, portanto, a 6,85\% de acidez obtidos por Abreu et al. (2009). Esses autores encontram grande variabilidade das medidas de acidez em função dos diferentes genótipos de maracujá e da época de colheita. Coelho et al. (2010) verificaram que o maracujá-amarelo comum colhido maduro atinge $4,42 \%$ de acidez. Segundo Silva et al. (2008) os maracujás colhidos mais verdes no inverno são mais ácidos que os da safra de verão; contudo, a acidez reduz à medida em que os frutos amadurecem. Os maracujás comuns colhidos maduros na safra de verão apresentam média de acidez de $4,09 \%$ e os colhidos na safra de inverno alcançam $4,64 \%$ de acidez.

$\mathrm{O}$ consumo de ácidos orgânicos no estádio 1 foi indicado também pelo aumento de $\mathrm{pH}$ mas, a partir do estádio 2 , não ocorreram diferenças com relação aos frutos maduros. $\mathrm{O} \mathrm{pH}$ do suco da cultivar BRS GA foi de 3,02 $( \pm 0,18)$ em conformidade, portanto, com o trabalho de Abreu et al. (2009) que encontraram valores de $\mathrm{pH}$ de 3,08 .

Nas análises de ácido ascórbico (AA) ao contrário dos demais estádios de maturação, os frutos do estádio 1 reduziram o teor de AA durante a estocagem, notadamente para as cultivares BRS GA e BRS SC (Figura 4). Coelho et al. (2010) identificaram um expressivo consumo de AA durante o armazenamento de maracujás-amarelos colhidos imaturos. Segundo Cerqueira et al. (2011) os maracujás colhidos imaturos reduzem o teor de AA na estocagem em razão do metabolismo mais intenso.

As médias de ácido ascórbico do suco de frutos maduros

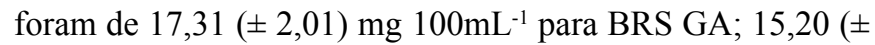
$2,41) \mathrm{mg} 100 \mathrm{~mL}^{-1}$ para BRS SC e $15,52( \pm 1,79) \mathrm{mg} 100 \mathrm{~mL}^{-1}$ para BRS OV. Tupinambá et al. (2008) encontraram índices de

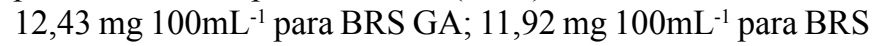

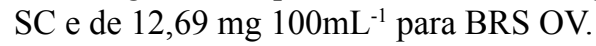

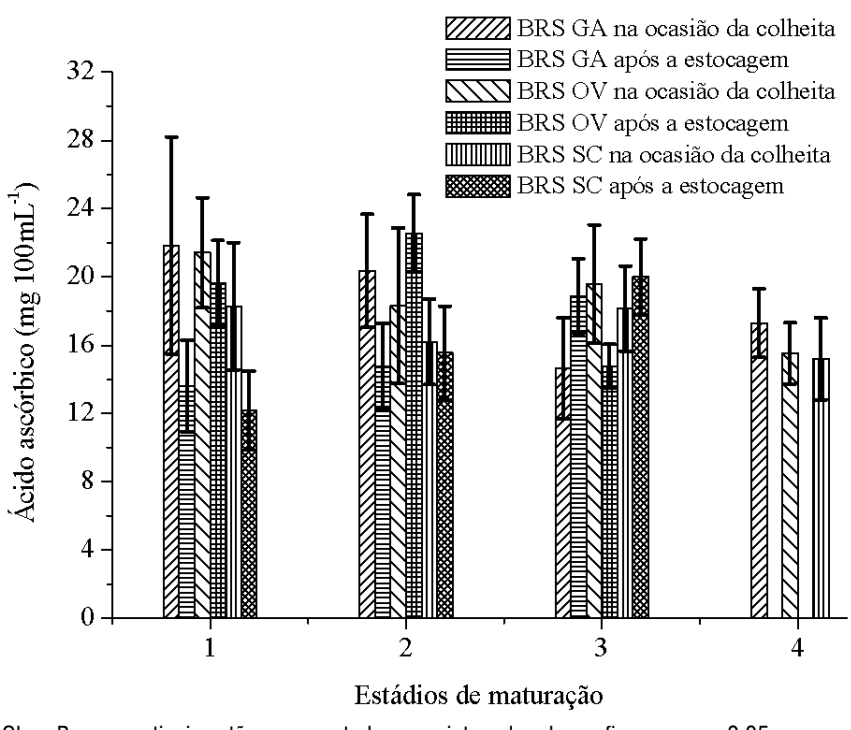

Obs.: Barras verticais estão representadas com intervalos de confiança a $p \leq 0,05$

Figura 4. Teor de ácido ascórbico do suco de BRS Gigante Amarelo (BRS GA), BRS Ouro Vermelho (BRS OV) e BRS Sol do Cerrado (BRS SC) avaliados em diferentes estádios de maturação e após o amadurecimento em câmara a $22{ }^{\circ} \mathrm{C}$ e $90 \%$ UR

\section{Conclusões}

1. As três cultivares de maracujá: BRS Gigante Amarelo, BRS Ouro Vermelho e BRS Sol do Cerrado, adquirem o ponto ótimo de colheita na safra de verão quando apresentam pelo menos $55 \%$ de coloração amarela na casca.

2. Os frutos da safra de verão colhidos com menos de $55 \%$ de coloração amarela da casca são considerados imaturos e apresentam maior perda de massa e queda excessiva do conteúdo de ácido ascórbico, além de redução da acidez e de açúcares, durante a estocagem.

3. A colheita antecipada dos frutos com 55\% de coloração amarela da casca preserva a qualidade dos maracujás e lhe aumenta a vida útil, durante o armazenamento.

\section{Agradecimentos}

Ao $\mathrm{CNPq}$, pelo apoio financeiro ao Projeto Processo $\mathrm{n}^{\circ}$ 554408/2006-6 e pela Bolsa de Desenvolvimento Tecnológico e Extensão Inovadora (DT); à FAPERJ pelo apoio financeiro; à CAPES, pela Bolsa de Mestrado e ao Sr. Edinei Tavares Sentineli, pela produção dos frutos.

\section{Literatura Citada}

Abreu, S .P. M.; Peixoto, J. R.; Junqueira, N. T. V.; Sousa, M. A. F. Características físico-químicas de cinco genótipos de maracujazeiro-azedo cultivados no Distrito Federal. Revista Brasileira de Fruticultura, v.31, p.487-491, 2009.

AOAC - Association of Official Agricultural Chemists. Official Methods of Analysis of AOAC International, 16.ed., Gaithersburg: AOAC International, 1994. 1298p.

Cerqueira, F. O. S.; Resende, E. D.; Martins, D. R.; Santos, J. L. V.; Cenci, S. A. Qualidade do maracujá-amarelo armazenado sob refrigeração em atmosfera controlada. Ciência e Tecnologia de Alimentos, v.31, p.526-532, 2011.

Chitarra, M. I. F.; Chitarra, A. B. Pós-colheita de frutas e hortaliças: Fisiologia e Manuseio. Lavras: ESAL/FAEPE, 2005. 785p.

Coelho, A. A.; Cenci, S. A.; Resende, E. D. Qualidade do suco de maracujá-amarelo em diferentes pontos de colheita e após o amadurecimento. Ciência e Agrotecnologia, v.34, p.722-729, 2010.

Coelho, A. A.; Cenci, S. A.; Resende, E. D. Rendimento em suco e resíduos de maracujá em função do tamanho dos frutos em diferentes pontos de colheita para o armazenamento. Revista Brasileira de Produtos Agroindustriais, v.13, p.55-63, 2011 a.

Coelho, A. A.; Oliveira, E. M. S.; Resende, E. D.; Thiébaut, J. T. L.. Dimensionamento amostral para a caracterização da qualidade pós-colheita do maracujá-amarelo. Revista Ceres, v.58, p.23-28, $2011 \mathrm{~b}$.

Faleiro, F. G.; Junqueira, N. T. V.; Braga, M. F.; Peixoto, J. R. Caracterização de Germoplasma e Melhoramento Genético do Maracujazeiro Assistidos por Marcadores Moleculares: resultados da pesquisa 2005-2008. Boletim de Pesquisa e Desenvolvimento. Planaltina: Embrapa Cerrados, 2008. $58 \mathrm{p}$. 
IBGE - Instituto Brasileiro de Geografia e Estatística. Diretoria de Pesquisa, Coordenação de Agropecuária, Produção Agrícola Municipal 2010. http://www.ibge.gov.br/home/ download/estatistica.shtm>. 15 Dez. 2011.

Junqueira, N. T. V.; Anjos, J. R. N.; Silva, A. P. O.; Chaves, R. C.; Gomes, A. C. Reação às doenças e produtividade de onze cultivares de maracujá-azedo cultivadas sem agrotóxicos. Pesquisa Agropecuária Brasileira, v.38, p.1005-1010, 2003.

Lane, J. H.; Eynon, L. Determination of reducing sugars by Fehling's solution with methylene blue indicator. London: Normam Rodge1934. 8p.

Lima, A. A. Maracujá produção: Aspectos técnicos. Brasília: Embrapa Informação Tecnológica, 2002. 103p. Frutas do Brasil, 15

Martins, D. R. Qualidade pós-colheita do mamão armazenado sob refrigeração em condições de atmosfera controlada. Campos dos Goytacazes: UENF, 2005. 98p. Dissertação Mestrado

Pinheiro, A. M.; Fernandes, A. G.; Fai, A. E. C.; Prado, G. M.; Sousa, P. H. M.; Maia, G. A. Avaliação química, físicoquímica e microbiológica de sucos de frutas integrais: abacaxi, caju e maracujá. Ciência e Tecnologia de Alimentos, v.26, p.98-103, 2006.
SAEG. Sistema para análises estatísticas. Versão 9.1: Viçosa: Fundação Arthur Bernardes/UFV, 2007. 301p.

Santos, J. L. V. Qualidade dos frutos e ponto de colheita das cultivares de maracujá: BRS Gigante Amarelo, BRS Ouro Vermelho, BRS Sol do Cerrado. Campos dos Goytacazes: UENF, 2011. 93p. Dissertação Mestrado

Silva, T .V.; Resende, E. D.; Viana, A. P.; Pereira, S. M. F.; Carlos, L. A.; Vitorazi, L. Determinação da escala de coloração da casca e do rendimento em suco do maracujáamarelo em diferentes épocas de colheita. Revista Brasileira de Fruticultura, v.30, p.880-884, 2008.

Tupinambá, D. D.; Costa, A. M.; Cohen, K. O.; Paes, N. S.; Faleiro, F. G.; Campos, A. V. S.; Santos, A. L .B.; Silva, K. N.; Faria, D. A. Caracterização físico-química e funcional de polpas de híbridos comerciais de Passiflora edulis f. flavicarpa Deg. da safra outubro/2007 sob diferentes condições de armazenamento. In: Simpósio Nacional Cerrado, 9.; Simpósio Internacional Savanas Tropicais, 2, 2008, Brasília. Desafios e estratégias para o equilíbrio entre sociedade, agronegócio e recursos naturais. Anais... Planaltina: Embrapa Cerrados, 2008, CD-Rom 